\title{
Parâmetros relacionados ao conforto de passageiros: uma pesquisa das práticas adotadas por fabricantes de poltronas
}

\author{
Jerusa Barbosa Guarda de Souza ${ }^{\mathrm{a} *}$, Nilton Luiz Menegon ${ }^{\mathrm{b}}$, \\ Marina Greghi Sticca ${ }^{\mathrm{c}}$, Talita Naiara Rossi ${ }^{\mathrm{d}}$ \\ a*jerusaguarda@gmail.com, UFSCar, SP, Brasil \\ ${ }^{\mathrm{b}}$ menegon@dep.ufscar.br, UFSCar, SP, Brasil \\ 'marinagreghi@dep.ufscar.br, UFSCar, SP, Brasil \\ dtalitanrossi@gmail.com, UFSCar, SP, Brasil
}

\begin{abstract}
Resumo
0 processo de desenvolvimento de produtos é um processo interdisciplinar que engloba o estudo das pessoas, dos processos e do contexto. A inserção da ergonomia ao projeto de produtos tem ganhado importância nos últimos anos. No transporte de passageiros, esse assunto é importante e o conforto sentado possui relevância considerável na percepção dos usuários. Neste estudo, buscou-se levantar as práticas de inserção de ergonomia e conforto ao processo de desenvolvimento de produtos, adotadas por fabricantes de poltronas. 0 referencial teórico utilizado foi o modelo de desenvolvimento de produtos proposto por Pugh (1983), Pugh e Morley (1986) apud Pugh (1996). Partindo da literatura existente e de entrevistas semiestruturadas realizadas em cinco fabricantes de poltronas, identificou-se que a ergonomia e o conforto têm sido considerados como parâmetros no processo de desenvolvimento de produtos destas empresas. No entanto, não se observou a consolidação da análise da atividade de usuários enquanto metodologia universalmente consolidada.
\end{abstract}

Palavras-chave

Conforto. Ergonomia. Poltrona. Transporte.

\section{Introdução}

No campo da Engenharia existe uma ampla literatura sobre o processo de desenvolvimento de produtos (PAHL; BEITZ, 1995; PUGH; MORLEY, 1986 apud PUGH, 1996; CLARK; WEELWRIGHT, 1993; ROZENFELD et al., 2006).

Pahl e Beitz (1995) apresentam em sua obra Engineering design: a systematic aproach uma revisão histórica e os principais métodos existentes na área, enfatizando também a natureza interativa do processo de projeto que inviabiliza uma rigidez das etapas. As experiências práticas dos autores mostram a necessidade de se propor um modelo flexível para o processo de desenvolvimento de produto.

0 modelo proposto por Pugh (1983), Pugh e Morley (1986) apud Pugh (1996), busca atender a esta flexibilidade. Os autores apresentam uma abordagem para a teoria geral do projeto que busca integrar a psicologia social dos grupos com trabalhos no campo de projeto de engenharia. Tal abordagem busca identificar as principais áreas da atividade de projeto, mostrando como elas relacionam-se e, em cada área, especificando seus mais importantes elementos, integrando estas ideias principais em um modelo que pode ser usado em qualquer atividade de projeto.

Assim, o modelo de desenvolvimento de produto é composto por uma parte central que pode ser moldada pela natureza das especificações (Product Design Specification). Esta parte central é a principal área da atividade de projeto, comum para todos os projetos e formada por: investigação de mercado; especificação do projeto do produto; projeto conceitual; projeto 
detalhado; manufatura e vendas. Uma vez que o núcleo central é comum a todos os tipos de projeto, fica a cargo das outras áreas da atividade dar ao projeto suas características peculiares, através de diferentes tipos de informação, técnicas e gerenciamento (PUGH, 1996).

Estes autores afirmam ainda que o processo de desenvolvimento de produto é um processo interdisciplinar que engloba o estudo das pessoas (atividade), dos processos (gestão) e do contexto (estratégias). A abordagem das estratégias considera a inserção do projeto do produto no contexto mais amplo dos negócios, abordando os aspectos gerenciais e as atividades dos projetistas associados às distintas estratégias existentes na empresa.

A abordagem da gestão abrange os processos que constroem uma rede de relações no projeto, ressaltando a importância da gestão do processo de projeto. Por fim, temos a abordagem da atividade, segundo a qual o desenvolvimento de produtos envolve várias dimensões, especialmente as pessoas e profissionais relacionados; suas atividades; as metodologias, ferramentas e decisões (PUGH, 1996).

Bucciarelli (1990) complementa essa definição ao afirmar que é importante que o design seja visto como um processo social dinâmico, em que os diferentes mundos objetos dos atores sejam reconhecidos e negociados ao longo de todo o projeto, tendo como foco final atender às necessidades dos usuários.

Nesta perspectiva, para Falzon (2005), a aplicação da metodologia ergonômica, principalmente da análise da atividade, tem trazido, nos últimos anos, resultados significativos para o processo de desenvolvimento de produto, fazendo com que as empresas invistam em iniciativas de integração de aspectos ergonômicos.

Assim, nos últimos anos, as contribuições da ergonomia ao longo do processo de desenvolvimento de produto têm gerado vantagem competitiva (IIDA, 2005; SABINO NETTO et al., 2004).

Para Valot (2007), os conhecimentos da ergonomia devem ser aplicados à indústria de transporte de passageiros, dada a imensa combinação de contextos e constrangimentos para os usuários e a transformação das suas necessidades. Antigamente, itens como segurança, rapidez e economia eram itens prioritários no mundo dos transportes. Porém, desde a década de 70 , estudos de ergonomia revelam uma preocupação com o conforto do usuário (OBORNE; CLARKE, 1973; OBORNE, 1978; JACOBSON; MARTINEZ, 1974).

Em relação ao conforto de passageiros, os últimos estudos têm mostrado que o conforto sentado possui relevância considerável na percepção de satisfação dos usuários. Um estudo realizado no setor aéreo, por exemplo, mostra que uma das principais reclamações dos passageiros é com relação aos fatores da poltrona e com o pouco espaço destinado a eles (INTERNATIONAL..., 2009).

A revisão bibliográfica sobre práticas de ergonomia na indústria de poltronas apontou que muitos estudos dedicam-se à prescrição de parâmetros “ideais" para diferentes tipos de cadeiras e poltronas (KEEGAN, 1953; HARRISON, 1999; PANERO; ZELNIK, 2002; IIDA, 2005).

Porém, somente conhecer os parâmetros isolados inerentes ao projeto de poltronas não as torna ergonômicas, sobretudo porque, segundo lima (2000), a condição de "ser ou não ergonômica” não é algo que diz respeito apenas ao mobiliário, mas também é dependente da relação que se estabelece entre o objeto e o corpo do usuário, em uma determinada atividade.

Uma revisão da literatura do setor de transportes, principalmente do setor automobilístico e ferroviário, apontou que a análise da atividade do passageiro vem se consolidando como uma metodologia utilizada para levantar parâmetros de conforto/desconforto (BRONKHORST; KRAUSE, 2005; HAN et al., 1998; JACOBSON; MARTINEZ, 1974; BRANTON, 1969).

Estudos em poltronas de operadores (tratores, por exemplo) mostram que muitos fatores podem influenciar o conforto sentado, tais como o suporte postural fornecido ao corpo, a distribuição da pressão e as propriedades térmicas. Existem normas que estabelecem as "dimensões ótimas" para poltronas de tratores, como a ISO 4253, mas de acordo com Dhingra, Tewari e Singh (2003), não há uma poltrona ideal capaz de fornecer suporte a todas as posturas assumidas pelo operador durante seu trabalho, ressaltando a importância de se analisar sua atividade.

$\mathrm{Na}$ indústria automobilística, de acordo com Kyung, Nussbaum e Babski-Reeves (2008), falar de conforto para motoristas de automóveis é diferente de falar de conforto em cadeiras de escritório, uma vez que o primeiro envolve maiores restrições da postura em um espaço limitado, várias atividades de controle e inclui ainda o fator vibração, que pode levar a desordens musculoesqueléticas.

$\mathrm{Na}$ indústria ferroviária, é relevante o estudo de Bronkhorst e Krause (2005), que utilizou a observação do comportamento de passageiros durante a viagem para projetar poltronas confortáveis para passageiros de trens.

Outro estudo proposto por Branton e Grayson (1967), também na indústria ferroviária, observou o comportamento sentado de viajantes de trem, mostrando que o grau de estabilidade que uma poltrona oferece pode ser aferido observando as atividades compensatórias por parte do sujeito que está sentado, como por exemplo, a modificação da postura. 
Também para Han et al. (1998), o conforto dos passageiros de trens depende não somente do espaço alocado entre as poltronas, mas também da possibilidade de realização das atividades pretendidas por eles.

$\mathrm{Na}$ indústria aeronáutica, verificou-se a existência de poucos estudos utilizando a análise das atividades dos passageiros como metodologia para levantar a percepção dos passageiros sobre aspectos relacionados ao conforto/desconforto. No entanto, esse assunto é relevante, como mostra um estudo de Richards, Jacobson e Kuhlthau (1978), que utilizou como fontes de dados questionários administrados a bordo de vôos comerciais. Os resultados mostraram que as percepções de conforto diminuem proporcionalmente ao aumento dos constrangimentos à atividade que o passageiro quer desempenhar. Jacobson e Martinez (1974) também compartilham a opinião de que a facilidade ao realizar as atividades é um determinante importante na percepção do conforto/desconforto.

Dessa forma, depois da revisão da literatura, constatou-se a necessidade de levantar as práticas atuais da indústria de transportes em termos de inserção de ergonomia e conforto ao projeto de seus produtos.

\section{Objetivo}

0 objetivo geral desta pesquisa foi investigar como as empresas fabricantes de poltronas para a indústria de transportes inserem aspectos relacionados à ergonomia e ao conforto ao processo de desenvolvimento de seus produtos. 0 objetivo específico foi levantar os principais conceitos, metodologias e ferramentas utilizadas, através da realização de um benchmarking, investigando, sobretudo, se a análise da atividade dos usuários finais é considerada no projeto e a forma como ela é feita.

\section{Método}

A abordagem utilizada na pesquisa foi a abordagem qualitativa. Esta abordagem tem como características principais a falta de domínio completo sobre as variáveis, a ênfase na perspectiva daqueles que estão sendo estudados e a ênfase na observação de situações e análise de documentos (CRESWELL, 1997).

0 método escolhido nesta fase da pesquisa foi o estudo de caso. Em geral, este método é escolhido quando se colocam questões do tipo "como" e "por que”, uma vez que estas são questões explanatórias que lidam com ligações operacionais que devem ser traçadas ao longo do tempo, em vez de serem encaradas como meras repetições ou incidências (YIN, 2005).
Os estudos de caso podem ser utilizados para diferentes tipos de objetivos de pesquisa, tais como exploração, construção de teoria, teste de teoria e aprimoramento de uma teoria já existente (VOSS; TSIKRIKTSIS; FROHLICH, 2002). Meredith (1998) apud Voss, Tsikriktsis e Frohlich (2002) afirma que o estudo de caso pode ser utilizado para estudar práticas atuais existentes em uma empresa e para explorar precocemente variáveis ainda desconhecidas e fenômenos que não são muito bem compreendidos, caso da pesquisa vigente. Na pesquisa em questão o estudo de caso será utilizado como ferramenta exploratória, para estudar práticas atuais utilizadas em empresas.

Uma particularidade dos estudos de caso é que eles podem ser estudos de caso único ou de casos múltiplos. A pesquisa vigente utilizará estudos de casos múltiplos para analisar as questões de pesquisa. Geralmente projetos de casos múltiplos apresentam evidências consideradas mais convincentes do que nos estudos de caso únicos, e o estudo global é visto como algo mais robusto (HERRIOTT; FIRESTONE, 1983 apud YIN, 2005).

Tipicamente, o recurso mais utilizado para a coleta de dados no estudo de caso são as entrevistas estruturadas, mas também podem ser utilizadas entrevistas não estruturadas e interações. Outras fontes de dados incluem: observações pessoais, conversas informais, presença em encontros e eventos, levantamentos administrados dentro da organização, coleção de dados objetivos e revisão de arquivos (VOSS; TSIKRITSIS; FROHLICH, 2002).

Nesta pesquisa, para identificar como as questões de ergonomia e conforto são inseridas ao projeto de desenvolvimento de produtos, realizou-se: levantamento de dados secundários referentes às normas, legislações, critérios de conforto e ferramentas adotadas pelas indústrias; e entrevistas semiestruturadas com os responsáveis pela área de desenvolvimento de produto de cinco fabricantes de poltronas do setor de transportes (setores automobilístico e rodoviário) (Tabela 1), as quais foram direcionadas por meio de um instrumento de coleta de dados.

0 instrumento de coleta de dados utilizado (Anexo 1) buscou direcionar a entrevista de maneira a levantar as principais práticas adotadas pelas empresas em relação a ergonomia e conforto no processo de projeto do produto. 0 protocolo era composto dos seguintes itens:

- Item 1: dados sobre a empresa, setor e ramo de atuação, produtos fabricados, cliente, e parcerias;

- Itens 2 e 3: conceitos de ergonomia e conforto utilizados pelas empresas; 
Tabela 1. Empresas participantes da pesquisa.

\section{Empresas}

P1 Fabricante de poltronas para o setor rodoviário e fornecedora de componentes para a indústria automotiva.

P2 Fabricante de poltronas e componentes para a indústria automobilística.

P3 Fabricante de componentes e estruturas de poltronas para a indústria automobilística.

P4 Fabricante de carrocerias para o setor rodoviário, incluindo a fabricação de poltronas.

P5 Fabricante de poltronas, interiores e componentes para a indústria automobilística.

Fonte: Tabela elaborada pelos autores.

- Item 4: estrutura da empresa para tratar de questões referentes à inserção desses conceitos;

- Item 5: formas de aplicação desses conceitos ao projeto dos produtos;

- Item 6: métodos e as ferramentas utilizadas por cada uma das empresas para inserir a ergonomia e o conforto nos seus produtos.

Previamente à visita à empresa, o instrumento de coleta de dados foi enviado ao responsável pelo setor, para que este tomasse conhecimento do assunto que seria tratado na entrevista. Depois da realização da entrevista, os dados foram tratados e, posteriormente, enviados aos entrevistados para validação.

Os dados foram analisados de maneira descritiva, tendo como base o modelo proposto por Pugh (1983), Pugh e Morley (1986), apud Pugh (1996), previamente descrito. Dessa forma, os dados foram categorizados de acordo com os itens a seguir:

- Abordagem estratégica: contexto estratégico das empresas em termos de inserção da ergonomia e conforto no processo de desenvolvimento de produto.

- Abordagem gestão: forma como os processos são organizados para tratar essas questões.

- Abordagem atividade: pessoas, ferramentas e atividades envolvidas nesse processo.

Os resultados serão apresentados no próximo tópico.

\section{Resultados}

\subsection{Estratégia}

De acordo com o modelo proposto por Pugh (1983), Pugh e Morley (1986) apud Pugh, 1996, a parte central do projeto sofre interferências não apenas dos elementos de especificação do projeto do produto, mas também da estrutura de negócios da empresa. Dessa forma, a abordagem das estratégias considera a inserção do projeto no contexto mais amplo dos negócios, considerando os aspectos gerenciais e as atividades dos projetistas associados às distintas estratégias existentes (PUGH, 1996).

A Tabela 2 evidencia as práticas de cada uma das empresas entrevistadas do ponto de vista da estratégia.
Através do benchmarking, foi possível observar que, em quatro das cinco empresas entrevistadas (P1, P2, P4, P5), os produtos são desenvolvidos de acordo com a opinião e com as especificações dos clientes, que são as montadoras. As especificações do produto, como cores, materiais, design, dureza, densidade da espuma e normas a serem atendidas são definidas pelas montadoras e repassadas às fabricantes que desenvolvem o produto conforme lhes é solicitado.

Conforme mencionado pelas empresas P1, P2 e P3, a inovação nos produtos ocorre a partir da demanda das montadoras, mas também existem iniciativas próprias da empresa.

Além disso, três das empresas entrevistadas (P3, P4 e $\mathrm{P} 5)$ mencionaram possuir parcerias com universidades e outras empresas.

Foi possível observar também que todas as empresas preocupam-se em integrar requisitos ergonômicos e de conforto ao projeto de produtos. No entanto, apesar da preocupação, na maioria das empresas não há uma definição concreta acerca dos conceitos de ergonomia e conforto adotados.

Apenas algumas empresas apresentaram definições de conforto. Dentre elas, a empresa C, por fabricar estruturas, definiu que essa condição é proporcional ao número e à variedade de ajustes disponíveis ao usuário. Já a empresa B relatou ser o nível de ruído emitido pela poltrona um fator determinante para a percepção de conforto do usuário. Nesta mesma empresa, de acordo com os entrevistados, a distribuição da pressão afeta a sensação de conforto por parte do usuário.

0 que pôde ser observado é que a participação da ergonomia ao projeto de produto muitas vezes se resume à aplicação dos princípios antropométricos ao produto final.

$\mathrm{Na}$ grande maioria dos casos, os conceitos de ergonomia e conforto utilizados pelos fabricantes são aqueles definidos pelas próprias montadoras. Geralmente, as montadoras realizam pesquisas e estudos relacionados a estes aspectos e repassam as informações para as fabricantes. Apesar desta prática, algumas se destacaram pelas análises realizadas, visando avaliar o conforto, assunto que será discutido no tópico Atividades. 
Tabela 2. Práticas das empresas entrevistadas em termos de estratégia.

\begin{tabular}{|c|c|}
\hline Empresas & Estratégia \\
\hline P1 & $\begin{array}{l}\text { - Os produtos da empresa são desenvolvidos juntamente e de acordo com a opinião dos clientes, que são as montadoras. } \\
\text { - Centros de pesquisas localizados na matriz realizam os estudos de ergonomia e conforto. } \\
\text { - Inovação ocorre sob demanda do cliente ou sob iniciativa própria. }\end{array}$ \\
\hline P2 & $\begin{array}{l}\text { - Os critérios de conforto e segurança são especificados pelas montadoras, que realizam pesquisas e estudos relacionados a estes aspectos. } \\
\text { - A empresa possui um centro tecnológico que realiza testes tanto para os projetos da própria empresa, quanto para as concorrentes. } \\
\text { - A pesquisa de inovação ocorre em parceria com as montadoras ou por iniciativa própria. } \\
\text { - A empresa possui um sistema de rastreamento e acompanhamento das reclamações dos clientes, em conjunto com as montadoras. }\end{array}$ \\
\hline P3 & $\begin{array}{l}\text { - Os conceitos de ergonomia e conforto da empresa dependem de cada produto e são especificados pela montadora. } \\
\text { - De acordo com a visão da empresa, a percepção de conforto do usuário varia de acordo com o número e a variedade de opcionais } \\
\text { de ajuste que este puder escolher. } \\
\text { - A empresa possui um centro de benchmarking localizado na matriz responsável pela realização das pesquisas. } \\
\text { - Recentemente, negociou uma parceria com uma universidade paulista, com o objetivo de pesquisar novos materiais para a } \\
\text { fabricação de seus produtos. } \\
\text { - A empresa brasileira realiza um trabalho de pesquisa de inovação paralelo às exigências dos clientes, ou seja, sem sua demanda. }\end{array}$ \\
\hline P4 & $\begin{array}{l}\text { - Os conceitos de ergonomia (principalmente antropometria e segurança) e relacionados ao conforto estão inseridos desde a } \\
\text { concepção, na fase de análise de mercado. } \\
\text { - Buscam formas de medir a percepção de conforto dos usuários, de forma a construírem banco de dados quantitativos e qualitativos } \\
\text { que são, posteriormente, utilizados como requisitos de projetos. } \\
\text { - A empresa possui parceria com uma universidade brasileira para a qual solicita serviços e joint-venture para fabricação de espuma. } \\
\text { - De acordo com a visão da empresa, a atividade de inovação deve aumentar as possibilidades do projeto e, para isso, deve ter um } \\
\text { olhar divergente e fazer inovações em um ambiente de projeto tradicional. }\end{array}$ \\
\hline P5 & $\begin{array}{l}\text { - Os conceitos de conforto adotados pela empresa são especificações da própria montadora. As questões de estilo (aspecto estético) } \\
\text { são trabalhadas conjuntamente com a montadora. } \\
\text { - A empresa possui um memorando de ergonomia do qual retira seus requisitos. } \\
\text { - O desenvolvimento de pesquisas de conforto é realizado em um Centro de Desenvolvimento e Pesquisa na matriz, mas há } 1 \text { ano foi } \\
\text { inaugurado um Centro de Pesquisa no Brasil, com o objetivo de estudar aspectos ergonômicos, novos produtos e desenvolvimento } \\
\text { de novos projetos. } \\
\text { - O estabelecimento de parceiras depende do projeto a ser executado: a empresa desenvolve tecnologia no caso de projetos muito } \\
\text { grandes e compra outras para projetos menores. }\end{array}$ \\
\hline
\end{tabular}

\subsection{Gestão}

A abordagem da gestão abrange os processos que constroem uma rede de relações no projeto, ressaltando a importância da gestão do processo de projeto (PUGH, 1996). Foi possível verificar através dos resultados descritos que existem processos bem estruturados na maioria das empresas na atividade de desenvolvimento de produto. A Tabela 3 mostra as práticas das fabricantes.

Por meio do benchmarking, foi possível observar que, na maioria dos casos, a equipe parte das especificações das montadoras para desenvolver um determinado produto, a partir de poltronas-base. Em uma das empresas que mencionou realizar investigação de mercado para analisar o posicionamento do produto no mercado e a necessidade de criação (P4), a equipe de desenvolvimento de produto cria parâmetros projetuais, analisando as normas locais e regionais e os dados da análise de uso, postural e acional e da análise de conforto baseado na etnografia.

Um fator que deve ser discutido neste tópico é a forma como se dá a interação entre as equipes dentro de um mesmo projeto. Uma das empresas (P5) mencionou ter tido dificuldades neste sentido, pois, há cerca de um ano, foi estipulado que o ergonomista deveria participar desde a fase de concepção de projeto. Os entrevistados relataram que esse processo foi trabalhoso, pois foi preciso fazer uma sensibilização da equipe de projeto (engenheiros e designers), a fim de explicar conceitos básicos de ergonomia e a importância de considerá-los no projeto, a fim de evitar problemas futuros tanto na produção quanto no conforto percebido pelo usuário. Nessa empresa, o ergonomista parte das informações em 2D ou 3D geradas pela engenharia de aquisição para incluir as análises e sugestões de melhorias, baseado em informações vindas de projetos anteriores e de um banco de dados de melhores práticas mundiais adotadas em projetos da empresa.

Nas outras empresas entrevistadas, não foi observada essa dificuldade, talvez pelo fato desta atividade de desenvolvimento de produto ser realizada na maior parte das vezes por uma equipe mais homogênea.

Conforme discutido acima, as fabricantes trabalham em conjunto com as montadoras, enviando protótipos do produto para que estas avaliem se o projeto está de acordo com as especificações. Essa técnica é bastante útil no sentido de evitar gastos de reprojeto nas fases adiantadas do processo. Porém, a empresa P2 mencionou que algumas montadoras oferecem restrições à montagem do protótipo devido a questões de custo do projeto e de sigilo de informações.

Além disso, P1, P3 e P5 mencionaram trabalhar em conjunto com a matriz, compartilhando dados 
Tabela 3. Práticas das empresas entrevistadas em termos de gestão.

\begin{tabular}{|c|c|}
\hline Empresas & Gestão \\
\hline $\mathrm{P} 1$ & $\begin{array}{l}\text { - } 0 \text { projeto de um produto dura em média de } 2 \text { a } 3 \text { anos. Na Fase } 1 \text { do projeto, é realizada a negociação comercial e a empresa } \\
\text { define com o cliente as especificações do produto. Na fase } 2 \text {, a engenharia realiza o desenvolvimento do projeto do produto. } \\
\text { Nesta fase, são feitos desenhos, testes e as questões de ergonomia e conforto são tratadas. Na fase } 3 \text {, é definido o processo } \\
\text { para desenvolver o produto desejado. Na fase } 4 \text {, são realizados os detalhes de documentação com o cliente e na fase } 5 \text { ocorre o } \\
\text { feedback com o cliente, fase em que são coletadas as informações para melhoria nos projetos futuros. } \\
\text { - Geralmente, a empresa brasileira envia protótipos produzidos para a realização de testes na matriz, apesar do alto custo. }\end{array}$ \\
\hline $\mathrm{P} 2$ & $\begin{array}{l}\text { - Para projetar seus produtos, a equipe parte das especificações da montadora, verifica as opções no portfólio e elabora um protótipo } \\
\text { do produto. Este protótipo passa pela fase de Design Verification, na qual a empresa apresenta relatórios para montadoras e } \\
\text { designers para verificar se o protótipo está de acordo com as especificações. } \\
\text { - As montadoras oferecem restrições à montagem do protótipo devido a questões de custo do projeto e de sigilo de informações. }\end{array}$ \\
\hline P3 & $\begin{array}{l}\text { - O tempo de desenvolvimento de um produto varia de } 1 \text { ano e meio a } 2 \text { anos. A partir das especificações recebidas da montadora, } \\
\text { a equipe de desenvolvimento de produto desenvolve protótipos do produto, que são testados pelos clientes e se aprovados, são } \\
\text { encaminhados para a produção. } \\
\text { - A empresa no Brasil trabalha em conjunto com a matriz. Qualquer revisão do desenho de um produto ou modificação interna } \\
\text { visando à melhoria contínua deve passar pela fase de simulações novamente. }\end{array}$ \\
\hline P4 & $\begin{array}{l}\text { - } 0 \text { processo de design inicia-se com a compreensão do objetivo estratégico da empresa pela equipe. A partir disso, inicia-se o } \\
\text { escopo do projeto com a criação dos parâmetros projetuais. Para determinar esses parâmetros, são analisadas primeiramente as } \\
\text { normas locais e regionais (que dependem do mercado do produto). Em seguida, é feita uma análise de uso, postural e acional } \\
\text { (baseadas em banco de dados de projetos anteriores ou novas análises) e também uma análise do conforto baseado na etnografia, } \\
\text { através da consulta ao banco de dados das observações feitas dos usuários. Paralelamente à fase de Análise, estão sendo feitos } \\
\text { os trabalhos de Engenharia e ocorre uma interação das equipes ao longo do projeto. Também ao longo desta fase, ocorre o } \\
\text { processo de inovação, a fim de colocar inovações nos parâmetros projetuais. }\end{array}$ \\
\hline P5 & $\begin{array}{l}\text { - Há cerca de } 1 \text { ano a empresa instituiu que o ergonomista deveria participar desde a fase de concepção do projeto. } \\
\text { - A empresa possui um Program Management System (PMS), no qual cada programa é dividido em projetos, com definição } \\
\text { das áreas que devem ser envolvidas em cada uma de suas fases. Os programas são subdivididos em fases. A primeira fase é a } \\
\text { cotação (acquisition), na qual o cliente repassa para a empresa as especificações do produto como o estilo do veículo e a medida } \\
\text { da poltrona (tamanho, tipo de revestimento, densidade da espuma). A partir dessas informações, a Engenharia de Aquisição inicia } \\
\text { o Programa. Esta deve apresentar para o Ergonomista informações do produto em 2D ou 3D. A partir destas, o ergonomista } \\
\text { coloca recomendações em relação à ergonomia e conforto (informações vindas de projetos anteriores e de um banco de dados } \\
\text { de melhores práticas mundiais adotadas em projetos da empresa). Estes guidelines são alimentados pela matriz e todo projeto } \\
\text { deve ser iniciado consultando este material. }\end{array}$ \\
\hline
\end{tabular}

Fonte: Tabela elaborada pelos autores.

de benchmarking, medidas e normas adquiridas através de pesquisas realizadas em centros de desenvolvimento localizadas nas matrizes. Uma das empresas entrevistadas (P3) explicou que qualquer revisão do desenho de um produto da empresa brasileira deve ser comunicada à matriz. Da mesma forma, qualquer modificação interna visando à melhoria contínua deve passar pela fase de simulações novamente.

Em suma, foi observado que todas as empresas entrevistadas consideram os aspectos de ergonomia e conforto nas fases iniciais do projeto, seja através de especificações do cliente ou até mesmo de estudos realizados internamente.

\subsection{Atividade}

De acordo com a abordagem da atividade, o desenvolvimento de produtos incorpora numerosas variáveis, incluindo as pessoas e profissionais envolvidos no projeto, suas atividades, metodologias, ferramentas e decisões (PUGH, 1996). A Tabela 4 mostra as práticas das empresas, ressaltando, sobretudo a equipe responsável pela inserção dos aspectos de ergonomia e conforto ao projeto de produtos e as ferramentas utilizadas para tal propósito.
Em todas as empresas entrevistadas, a equipe responsável por inserir os conceitos de ergonomia e conforto ao projeto é a própria equipe de desenvolvimento de produtos composta, na maioria das empresas, por engenheiros, designers e técnicos. Apenas uma das empresas entrevistadas mencionou ter na equipe um ergonomista (P5).

Dentre as atividades desenvolvidas pelas equipes, identificou-se que estas se relacionam principalmente ao planejamento e desenvolvimento de projetos (novos ou em andamento), com propostas de melhoria contínua. Em algumas empresas, a equipe também atua na investigação do mercado (P4); pesquisas de campo com usuários (P4); concepção; realização de testes de segurança para projetos da própria empresa ou para as concorrentes (P2); pesquisa de inovação ( $\mathrm{P} 1$, P2, P3, P4, P5) e suporte a outras áreas.

$\mathrm{Na}$ empresa $\mathrm{P} 5$, na qual há um ergonomista na equipe de desenvolvimento de produto, o entrevistado mencionou que, além das atividades gerais da equipe, este profissional ainda atua em ergonomia industrial, principalmente no que se refere à análise de postos de trabalho e ao treinamento da equipe para realizá-las.

Pelos resultados apresentados pudemos observar que o conforto é apenas uma das especificações do produto. Muitos outros parâmetros de projeto foram 
Tabela 4. Práticas das empresas pesquisadas em termos de atividade.

\begin{tabular}{|c|c|}
\hline Empresas & Atividade (ferramentas e métodos) \\
\hline $\mathrm{P} 1$ & $\begin{array}{l}\text { Equipe: } \\
\text { - Engenheiros e técnicos. } \\
\text { Ferramentas e métodos: } \\
\text { - O dimensionamento de poltronas é feito a partir do ponto H (ponto de intersecção entre o dorso e as pernas). } \\
\text { - Análises de uso e dos locais onde serão utilizados os produtos, para que estes conceitos sejam analisados e introduzidos aos projetos. } \\
\text { - Relatórios de avaliação de conforto e dores realizadas em usuários de diferentes percentis antropométricos apresentados pelas } \\
\text { montadoras. } \\
\text { - Manual interno da empresa relativo à ergonomia em poltronas. } \\
\text { - Caderno com especificações antropométricas. } \\
\text { - Manequim Tridimensional, utilizando dados antropométricos brasileiros. } \\
\text { - Mapeamento de Pressão. } \\
\text { - Testes de resistência para verificar a durabilidade do produto: teste do bate-esfrega, teste de durabilidade de suspensão horizontal } \\
\text { e vertical, Falltest, teste de campo e ancoragem de cinto de segurança (ECE-R 14). } \\
\text { - Testes de Segurança realizados na matriz: Crashtest } \\
\text { - Normas: Europeias, Americanas e Norma interna da empresa. }\end{array}$ \\
\hline $\mathrm{P} 2$ & $\begin{array}{l}\text { Equipe: } \\
\text { - Engenheiros e técnicos } \\
\text { - Atividades: realizam testes solicitados pelas equipes internas da engenharia (desenvolvimento de projetos), prestam serviços para } \\
\text { outras empresas e alugam seus equipamentos de teste. Fazem pesquisa de inovação em relação às poltronas e painéis (em parceria } \\
\text { com as montadoras ou não). } \\
\text { Ferramentas e métodos: } \\
\text { - Dimensionamento de poltronas a partir do ponto H. } \\
\text { - Manequim Tridimensional com dados antropométricos americanos (simulação de diferentes percentis - 5\%F, 50\%M e 95\%M). } \\
\text { - Testes gerais para assegurar a resistência do produto: câmaras climáticas, teste de flamabilidade, teste de tração, simulador hidráulico. } \\
\text { - Testes Legais: Teste de simulação de colisão traseira e dianteira; teste do painel com o airbag, sliding entry (simula a entrada e a } \\
\text { saída do assento). } \\
\text { - Testes de Conforto: Mapeamento de Pressão; Testes de ruído emitido pela poltrona. } \\
\text { - Teste de Usabilidade: Craftmanship (verificar os acessos no interior do automóvel). } \\
\text { - Sistema de rastreamento e acompanhamento das reclamações dos clientes. }\end{array}$ \\
\hline P3 & $\begin{array}{l}\text { Equipe: } \\
\text { - Engenheiros e técnicos } \\
\text { - Atividades: planejam e desenvolvem, tanto novos projetos como projetos que estão em série, com propostas de melhoria contínua. } \\
\text { Ferramentas e métodos: } \\
\text { - Dimensionamento de poltronas a partir do ponto H. } \\
\text { - Utilizam dados antropométricos europeus e brasileiros. } \\
\text { - Usabilidade do produto: utilizam o software CATIA V4 e V5. } \\
\text { - Costumam fazer protótipos do produto. } \\
\text { - Teste de resistência e durabilidade. } \\
\text { - Utilizam dados de benchmarking vindos da matriz para o projeto. } \\
\text { - Segurança: fazem apenas testes de componentes. } \\
\text { - Normas: Resolução CONTRAN, Normas NBR, ECERs, FMVSS EWG, ADR. } \\
\text { - Sistema de Rastreabilidade. }\end{array}$ \\
\hline P4 & $\begin{array}{l}\text { Equipe: } \\
\text { - Designers e engenheiros } \\
\text { - Atividades: desenvolvimento de novos produtos e customização, mediante solicitação. } \\
\text { Ferramentas e métodos: } \\
\text { - Pesquisas de Mercado. } \\
\text { - Análise de Conforto: Pesquisa Etnográfica, com observações e filmagens de usuários. } \\
\text { - Validação com usuários reais após o projeto. } \\
\text { - Mock-ups físicos e virtuais e protótipo em escala real, sempre que houver aspectos de conforto e ergonomia envolvidos. } \\
\text { - Análise antropométrica dos usuários (medidas antropométricas baseadas em Dreyfuss e em dados das pesquisas de campo). Utilizam } \\
\text { percentil 97,5\% M e 2,5\%F. } \\
\text { - Manequins tridimensionais. } \\
\text { - Simulação em 3D. }\end{array}$ \\
\hline P5 & $\begin{array}{l}\text { Equipe: } \\
\text { - Ergonomista e Engenheiro. } \\
\text { - Atividades: Ergonomia Industrial (análise de postos de trabalho e treinamento da equipe para realizar estas análises); Ergonomia } \\
\text { de Produto (análises sobre possíveis problemas em relação à antropometria e conforto; recomendações e soluções). } \\
\text { Ferramentas e métodos: } \\
\text { - Dimensionamento de poltronas a partir do ponto H, ângulo do dorso, ângulo da coxa e coordenada do calcanhar em relação à } \\
\text { horizontal absoluta do ângulo do pé. } \\
\text { - Mock-ups físicos e virtuais. } \\
\text { - Desenhos e representações em 2D e 3D. } \\
\text { - Utilização do braço Romer, que substitui o Manequim Tridimensional e faz a análise a partir do Ponto H. } \\
\text { - Manequim Tridimensional. -Dados antropométricos utilizados são exigências das montadoras. Geralmente trabalham com percentil } \\
\text { 50\%M, se a montadora solicitar a empresa faz análise percentil 95\%M. } \\
\text { - Protótipos em escala real. } \\
\text { - Mapeamento de Pressão. } \\
\text { - Normas de segurança que variam de acordo com o mercado ao qual o produto se destina: FMVSS, CONTRAN, ECE-R. }\end{array}$ \\
\hline
\end{tabular}

Fonte: Tabela elaborada pelos autores. 
citados no processo de desenvolvimento de poltronas, dentre eles ergonomia, resistência e durabilidade, segurança, eficácia, custo, design, usabilidade e peso.

Em relação ao conforto, algumas empresas mencionaram a realização da análise da atividade de usuários para o projeto de seus produtos, corroborando com os dados da literatura que afirmam que observações de usuários sentados podem ser usadas para complementar os limites da tolerância ao desconforto (BRANTON, 1969).

Dentre estas empresas, a P1 mencionou que inicia um projeto levando em consideração os relatórios elaborados pelas montadoras, os quais apresentam avaliações de conforto e percepção de desconforto físico realizadas em usuários de diferentes percentis antropométricos. A mesma empresa mencionou ainda a realização de análises de uso e dos locais de atuação dos seus produtos.

Cabe ressaltar que os dados utilizados nas análises de conforto das montadoras são provenientes de estudos e pesquisas realizadas na matriz das empresas entrevistadas, as quais são, em geral, localizadas no exterior.

Outra empresa (P4) explicou que costuma realizar pesquisas etnográficas e também pesquisas de campo, com aplicação de questionários sobre conforto, registro de dados antropométricos, registros fotográficos e observações do usuário em situação de uso (situações reais), para entender às necessidades dos usuários. Essas informações alimentam um banco de dados que é consultado sempre antes da definição dos parâmetros projetuais.

O Mapeamento de Pressão mostrou-se uma ferramenta bastante difundida para a análise de conforto. Esta ferramenta é utilizada com usuários de diferentes percentis antropométricos, dependendo da exigência do cliente. Uma das empresas (P2) explicou inclusive que, antes da aplicação desta ferramenta, o conceito de conforto era muito subjetivo, passando a ser mais objetivo e palpável ao incorporar os dados provenientes destas análises. Juntamente com a análise objetiva através do mapeamento, é realizada uma avaliação subjetiva de conforto/desconforto através de questionário não padronizado, para validar as medidas. A literatura mostra que essa técnica é uma das mais utilizadas na avaliação de conforto/desconforto sentado (KÄRKI; LEKKALA, 2006; KOLICH, 2007).

Essa mesma empresa (P2) mencionou a realização de outro teste determinante na percepção de conforto do usuário. Conhecido como teste do ruído, uma poltrona é colocada em uma máquina que simula o uso dentro de um automóvel e nela é aferido o ruído emitido, não podendo ultrapassar $50 \mathrm{~dB}$.
Foi possível observar que, na maioria das empresas, o conceito de ergonomia é bastante subjetivo e, muitas vezes, se resume à adequação do projeto às características antropométricas dos usuários. Uma das empresas (P1) mencionou que utiliza um manual interno da empresa relativo à ergonomia em poltronas. Outra (P5) mencionou extrair informações de um memorando com requisitos ergonômicos, além de um catálogo com as melhores práticas adotadas por toda a empresa, contendo itens provenientes de projetos anteriormente desenvolvidos.

Com relação aos dados antropométricos, as empresas geralmente, utilizam dados brasileiros e/ ou europeus e/ou americanos (SAE), sendo esses últimos usados globalmente pelas montadoras. As empresas P4 e P5 mencionaram que utilizam dados antropométricos compatíveis com o mercado ao qual o produto se destina. Têm acesso a esses dados através de cadernos de especificações, dados de benchmarking realizados na maioria das vezes pela matriz, relatórios de clientes, pesquisas de campo, consulta ao Dreyfuss etc. Os percentis antropométricos utilizados variam com a especificação do cliente, geralmente, 5\%F e 95\%M. Apenas uma empresa (P4) trabalha com um percentil mais abrangente, considerando $2,5 \% \mathrm{~F}$ e $97,5 \% \mathrm{M}$.

0 manequim Tridimensional foi citado como ferramenta utilizada pelas empresas P1, P2, P4 e P5. Tal ferramenta é utilizada principalmente para o dimensionamento de poltronas a partir da medida do ponto $\mathrm{H}$, o qual corresponde à posição vertical relativa do quadril do ocupante, especificamente o ponto de pivô entre o dorso e as pernas. Apenas uma das empresas entrevistadas (P5) mencionou utilizar, além do ponto $\mathrm{H}$, outros pontos para projetar seus produtos. As outras medidas mencionadas foram 0 ângulo do torso, o ângulo da coxa e a coordenada do calcanhar em relação à horizontal absoluta do ângulo do pé.

Além do dimensionamento de poltronas, a empresa P2 mencionou que os manequins também são utilizados em alguns testes, quando se quer fazer uma simulação de longa duração como, por exemplo, no Mapeamento de Pressão. Uma das empresas (P5) mencionou a utilização de uma ferramenta conhecida como Braço Romer, que substitui o Manequim Tridimensional nessas análises.

Outro parâmetro de projeto bastante mencionado foi a segurança. Todas as empresas mostraram preocupações com esse fator, procurando adequar-se às normas exigidas pelos clientes (montadoras) e àquelas específicas do mercado ao qual o produto se destina; por exemplo, para mercado americano, costumam utilizar as FMVSS; para mercado europeu, as ECE-Rs, e para mercado brasileiro, as resoluções da NBR e do CONTRAN. Além das normas do mercado, 
algumas empresas, mencionaram que devem atender também a normas internas da empresa (P1), realizando ainda todos os testes obrigatórios de segurança, seja na própria empresa ou na matriz.

É relevante salientar que, conforme apontado por uma das empresas (P3), são realizados testes individuais de cada componente, cabendo à montadora a responsabilidade por testar todos estes integrados na avaliação final do veículo.

As empresas mencionaram que, dentre os fatores de projeto, aqueles determinantes nas decisões referem-se principalmente ao custo e à segurança. Assim, o conforto, por exemplo, apesar de ser importante não será considerado por si só, visto que as escolhas são feitas tendo em conta os compromissos de projeto (P1).

0 peso do produto foi outro parâmetro especificado por uma das empresas. De acordo com uma das empresas (P3), as montadoras têm solicitado cada vez mais a diminuição de peso das poltronas. Dessa forma, pesquisas de inovação em relação a novos materiais, espumas e estruturas vêm sendo realizadas.

A resistência e durabilidade do produto também são alvo de preocupação na maioria das empresas, sendo realizados testes específicos destinados a estas análises.

A eficácia do produto, outro parâmetro do projeto, foi especificada por uma das empresas (P2) e diz respeito à sua robustez, ou seja, seu tempo de vida.

Por fim, duas das empresas (P2 e P3) mencionaram a preocupação com a usabilidade do produto, realizando testes como o Craftmanship que verifica internamente o veículo, para que não ocorram problemas de acessibilidade, por exemplo. A simulação no CATIA (Computer Aided Three-dimensional Interactive Application) é outra ferramenta utilizada para evitar problemas de acessibilidade.

No que diz respeito à simulação, essa é uma ferramenta bastante utilizada no processo de desenvolvimento de produtos. As empresas entrevistadas mencionaram fazer uso de ferramentas como o FMEA (Failure modes and effect analysis), o Unigraffics e simulação em 2D e 3D para antecipar questões de ergonomia e/ou auxiliar na comunicação com as outras áreas participantes do projeto. A partir da simulação é possível desenvolver mock-ups físicos e virtuais e protótipos em escala real, para validação com usuários reais após o projeto. Somente uma das empresas (P2) mencionou que algumas montadoras evitam a construção de protótipos por questões de sigilo e custos.

Outra ferramenta observada foi um sistema de rastreabilidade, útil para acompanhar as reclamações dos clientes (em conjunto com as montadoras), ferramenta citada pela empresa $\mathrm{P} 2$.

\section{Conclusões e sugestões para pesquisas futuras}

Através dos dados do benchmarking foi possivel concluir que as empresas pesquisadas não possuem uma visão consolidada sobre os conceitos de ergonomia e conforto, apesar de considerarem importante a integração de tais aspectos ao processo de desenvolvimento de produtos. Além disso, a maioria das empresas analisadas recebe especificações em relação à ergonomia e conforto das montadoras de veículos.

Em relação às metodologias ergonômicas utilizadas, verificou-se que, apesar de algumas empresas utilizarem a análise da atividade de usuários, esta não é uma metodologia consolidada no mercado.

0 fato de algumas empresas receberem especificações da montadora em relação à ergonomia e conforto não inviabiliza a adoção de tal metodologia, conforme verificado em duas empresas analisadas. A primeira realiza análises de uso e dos locais de atuação, para levantar problemas e propor soluções em relação a tais aspectos, e a segunda realiza pesquisas etnográficas.

Faz-se importante também discutir que em apenas uma das empresas analisadas verificou-se a presença de um ergonomista na equipe de desenvolvimento de produto. Apesar do profissional ainda não ter conquistado espaço na área, os conhecimentos de ergonomia e conforto são difundidos nas empresas de outras formas, através da consulta a referências e materiais bibliográficos, por exemplo.

Em relação às ferramentas adotadas, verificou-se que o mapeamento de pressão é uma ferramenta largamente utilizada para análise de conforto. Os dados coletados corroboram com a revisão bibliográfica que aponta a necessidade de atrelar a aplicação de tal ferramenta a questionários subjetivos, de forma a validar os resultados obtidos.

Entretanto, conforme foi observado a partir dos dados coletados, esse teste é, na maioria das vezes, realizado com o usuário estático e, quando se quer simular o teste de longa duração, faz-se com o manequim tridimensional. Todavia, o ideal seria a realização do teste em condições reais com o usuário desempenhando as atividades típicas, a fim de levantar os principais constrangimentos em situação real para, a partir destas, propor soluções.

Conclui-se que os aspectos relacionados à ergonomia e ao conforto têm sido considerados no processo de desenvolvimento de produtos; no entanto, a análise da atividade de usuários não tem sido uma metodologia adotada pelas empresas pesquisadas. Além disso, não se verificou a realização de análises 
dinâmicas das atividades realizadas por usuários, o que poderia gerar dados consistentes para alterações no projeto relacionadas a aspectos ergonômicos e de conforto. Diante disso, a realização de pesquisas futuras, analisando os possíveis impactos da adoção desta metodologia nas melhorias relacionadas à ergonomia e conforto dos produtos, parece ser um caminho a ser adotado por empresas do setor pesquisado.

\section{Referências}

BRANTON, P. Behaviour, body mechanics and discomfort. Ergonomics, v. 12, n. 2, p. 316-327, 1969. PMid:5810917. http://dx.doi.org/10.1080/00140136908931055

BRANTON, P.; GRAYSON, G. An evaluation of train seats by observation of sitting behaviour. Ergonomics, v. 10, n. 1, p. 35-51, 1967. PMid:6036473. http://dx.doi. org/10.1080/00140136708930838

BRONKHORST, R. E.; KRAUSE, F. Designing comfortable passenger seats. In: VINK, P. Comfort and design: principles and good practice. Florida: CRC Press, 2005. p 155-167.

BUCCIARELLI, L. L. Ethnographic study and simulation of engineering design process. In: HELANDER, M.; NAGAMACHI, M. Design for Manufacturability and Process. Taylor \& Francis, 1990.

CLARK, K. B.; WEELWRIGHT, S. C. Managing new products and process development: text and cases. New York: The Free Press, 1993.

CRESWELL, J. W. Combined qualitative and quantitative designs. In: CRESWELL, J. W. Research design: qualitative and quantitative approaches. London: Sage, 1997. p. 173-192.

DHINGRA, H.; TEWARI, V.; SINGH, S. Discomfort, pressure distribution and safety in operator's seat: a critical review. Agricultural Engineering International: the CIGR Journal of Scientific Research and Development, v. 5, p. 1-15, 2003.

FALZON, P. Ergonomie, conception etdéveloppement. In: CONGRĖS DE LA SELF, 40., 2005, Paris. Anais... Paris, 2005, p. 21-23.

HAN, S. H. et al. Psycophysical methods and passenger preferences of interior designs. Applied Ergonomics, v. 29 , n. 6, p. 499-506, 1998. http://dx.doi.org/10.1016/ S0003-6870(97)00009-4

HARRISON, D. D. et al. Sitting Biomechanics Part 1: Review of the literature. Journal of Manipulative and Physiological Therapeutics, v. 22, n. 9, p. 594-609, 1999. http://dx.doi. org/10.1016/S0161-4754(99)70020-5

IIDA, 1. Ergonomia do Produto. In: IIDA, 1. Ergonomia Projeto e Produção. São Paulo: Edgard Blücher, 2005. p. 313-40.

INTERNATIONAL AIR TRANSPORTATION ASSOCIATION IATA. Corporate air travel survey. Montreal, 2009.

JACOBSON, D. 1.; MARTINEZ, J. The comfort and satisfaction of air travellers- basis for a descriptive model. Human Factors, v. 16, n. 1, p. 46-55, 1974.

KÄRKl, S.; LEKKALA, J. Pressure mapping system for physiological measurements. In: IMEKO WORLD CONGRESS - METROLOGY FOR A SUSTAINABLE
DEVELOPMENT, 28., 2006, Rio de Janeiro. Anais... Rio de Janeiro, 2006. p. 17-22.

KEEGAN, J. J. Alterations of the lumbar curve related to posture and seating. The Journal of Bone and Joint Surgery, v.35, p. 589-603, 1953.

$\mathrm{KOLICH}, \mathrm{M}$. A conceptual framework proposed to formalize the scientific investigation of automobile seat comfort. Applied Ergonomics, v. 39, n. 1, p. 15-27, 2007.

KYUNG, G.; NUSSBAUM, M. A.; BABSKI-REEVES, K. Driver sitting comfort and discomfort (part 1): use of subjective ratings in discriminating car seats and correspondence among ratings. International Journal of Industrial Ergonomics, v. 38, p. 516-525, 2008. http://dx.doi. org/10.1016/j.ergon.2007.08.010

LIMA, F. P. A. A ergonomia como instrumento de segurança e melhoria das condições de trabalho. In: SIMPÓSIO BRASILEIRO SOBRE ERGONOMIA E SEGURANÇA DO TRABALHO FLORESTAL E AGRÍCOLA ERGOFLOR, 1., 2000, Viçosa. Anais... Viçosa: Universidade Federal de Viçosa, 2000. p. 1-11.

SABINO NETTO, A. C. S. et al. Melhoria de produtos de uso doméstico com a aplicação da ergonomia integrada ao processo de projeto. In: ENCONTRO NACIONAL DE ENGENHARIA DE PRODUÇÃO - ENEGEP, 24., 2004, Florianópolis. Anais... ABEPRO, 2004. p. 2407-14.

OBORNE, D. J. Passenger comfort: an overview. Applied Ergonomics, v. 9, n. 3, p. 131-136, 1978. http://dx.doi. org/10.1016/0003-6870(78)90002-9

OBORNE, D. J.; CLARKE, M. J. The development of questionnaire surveys for the investigation of passenger comfort. Ergonomics, v. 16, n. 6, p. 855-869, 1973. http://dx.doi.org/10.1080/00140137308924577

PAHL, G.; BEITZ, W. The total design activity. In: PAHL, G.; BEITZ, W. Engineering Design- a systematic approach. Springer, 1995. p. 1-27.

PANERO, J.; ZELNIK, M. Antropometria dos assentos. In: PANERO, J.; ZELNIK, M. Dimensionamento humano para espaços interiores. Barcelona: Editorial Gustavo Gili AS, 2002. p. 57-67.

PUGH, S. The organization of design: an interdisciplinary approach to the study of people, process and contexts. In: PUGH, S. Creating innovative products using total design. Addison Wesley, 1996. p. 325-341.

RICHARDS, L. G.; JACOBSON, I. D.; KUHLTHAU, A. R. What the passenger contributes to passenger comfort. Applied Ergonomics, v. 9, n. 3, p. 137-142, 1978. http://dx.doi. org/10.1016/0003-6870(78)90003-0

ROZENFELD, $\mathrm{H}$. et al. Gestão de Desenvolvimento de Produtos: uma referência para melhoria de processo. São Paulo: Saraiva, 2006.

VALOT, C. 0 transporte, a segurança e a ergonomia. In: FALZON, P. Ergonomia. São Paulo: Editora Edgard Blücher, 2007. p. 573-586.

VOSS, C.; TSIKRIKTSIS, N.; FROHLICH, M. Case research in operations management. International Journal of Operations \& Production Management, v. 22, n. 2, p. $195-217,2002$. http://dx.doi. org/10.1108/01443570210414329

YIN, R. K. Introdução. In: YIN, R. K. Estudo de caso: planejamento e métodos. 3. ed. Porto Alegre: Bookman, 2005. p. 1-38. 


\section{Parameters related to passengers' comfort: a research on the practices adopted by seat manufacturers}

\section{Abstract}

The product development process is an interdisciplinary process which comprehends the study of the people, the processes and the context. Inserting ergonomics to the project of products has gained importance in the past years. This issue is important in the transportation of passengers, where comfort while seated has considerable relevance to the users' perception. The purpose of this study was to find out the practices of inserting ergonomics and comfort to the product development process adopted by seat manufacturers. The product development model presented by Pugh (1983) and Pugh; Morley (1986 and 1988) was the theoretical framework used. The work was based on the existing literature and semi-structured interviews with five seat manufacturers. It was observed that ergonomics and comfort are considered parameters in the products development processes of these companies. However, the consolidation of the analysis of users' activity as a universally consolidated methodology was not observed.

\section{Keywords}

Comfort. Ergonomics. Seat. Transportation.

Anexo 1. Instrumento de coleta de dados.

\begin{tabular}{|c|c|c|}
\hline Questões-chave & Palavras-chave & Evidências \\
\hline 1. Produção da empresa. & $\begin{array}{l}\text { Tipos de produto. } \\
\text { Clientes. } \\
\text { Parcerias. }\end{array}$ & Documentação - catálogos. \\
\hline 2. Conceito de conforto. & $\begin{array}{l}\text { Definições utilizadas. } \\
\text { Aplicações no projeto do produto. }\end{array}$ & Documentação - procedimentos de projeto. \\
\hline 3. Conceito de ergonomia. & $\begin{array}{l}\text { Definições utilizadas. } \\
\text { Aplicação em projetos. } \\
\text { Visão de higiene e segurança. }\end{array}$ & Documentação - procedimentos de projeto. \\
\hline $\begin{array}{l}\text { 4. Estrutura na empresa para tratar } \\
\text { as questões de ergonomia e } \\
\text { conforto. }\end{array}$ & $\begin{array}{l}\text { - Equipe responsável. } \\
\text { - Número. } \\
\text { - Formação, multidisciplinaridade. } \\
\text { - Parcerias (universidade, terceiros). } \\
\text { - Principais atividades da equipe. } \\
\text { - Processo (chegada da demanda, contato com outras áreas, } \\
\text { acompanhamento do projeto e das ações propostas pela } \\
\text { equipe, concepção de novos produtos). } \\
\text { - Resultados (mandatório, recomendações). } \\
\text { - Grau de autonomia. }\end{array}$ & $\begin{array}{l}\text { - Organograma. } \\
\text { - Fluxograma de atividades. } \\
\text { - Relatórios. }\end{array}$ \\
\hline $\begin{array}{l}\text { 5. Aplicação dos conceitos de } \\
\text { ergonomia e conforto no projeto } \\
\text { do produto. }\end{array}$ & $\begin{array}{l}\text { - Aspectos considerados. } \\
\text { - Em quais partes do produto são aplicados. }\end{array}$ & $\begin{array}{l}\text { - Procedimentos de projeto. } \\
\text { - Documentos - resultados. }\end{array}$ \\
\hline $\begin{array}{l}\text { 6. Abordagem dos aspectos da } \\
\text { ergonomia e conforto são } \\
\text { tratados no projeto do produto. }\end{array}$ & $\begin{array}{l}\text { - Segurança. } \\
\text { - Eficácia. } \\
\text { - Utilidade e usabilidade. } \\
\text { - Tolerância aos erros. } \\
\text { - Normas, procedimentos. } \\
\text { - Antropometria. } \\
\text { - Saúde. } \\
\text { - Relações sociais. } \\
\text { - Entretenimento. } \\
\text { - Estética (cor, formas). }\end{array}$ & $\begin{array}{l}\text { Metodologia e ferramentas utilizadas } \\
\text { - Pesquisas de mercado. } \\
\text { - Mapeamento de pressão*. } \\
\text { - Mock-ups e Protótipos. } \\
\text { - Ensaios e testes. } \\
\text { - Materiais*. } \\
\text { - Ferramentas específicas de análise de } \\
\text { conforto. } \\
\text { - Mecanismo de rastreabilidade. }\end{array}$ \\
\hline
\end{tabular}

